OPEN ACCESS

Edited by:

Jake Bailey,

University of Minnesota, USA

Reviewed by:

M. J. L. Coolen,

Curtin University, Australia Karen Elizabeth Rossmassler, Colorado State University, USA

*Correspondence: Xinhua Chen chenxinhua@tio.org.cn

Specialty section: This article was submitted to

Extreme Microbiology,

a section of the journal

Frontiers in Microbiology

Received: 31 July 2016 Accepted: 04 November 2016 Published: 18 November 2016

Citation: Guo W, Zhang H, Zhou W, Wang Y, Zhou H and Chen X (2016) Sulfur

Metabolism Pathways in Sulfobacillus acidophilus TPY, A Gram-Positive Moderate Thermoacidophile from a Hydrothermal Vent

Front. Microbiol. 7:1861. doi: 10.3389/fmich.2016.01861

\section{Sulfur Metabolism Pathways in Sulfobacillus acidophilus TPY, A Gram-Positive Moderate Thermoacidophile from a Hydrothermal Vent}

\author{
Wenbin Guo ${ }^{1}$, Huijun Zhang ${ }^{1,2}$, Wengen Zhou ${ }^{1,2}$, Yuguang Wang ${ }^{1}$, Hongbo Zhou ${ }^{2}$ and \\ Xinhua Chen ${ }^{1,3 *}$ \\ ${ }^{1}$ Key Laboratory of Marine Biogenetic Resources, Third Institute of Oceanography, State Oceanic Administration, Xiamen, \\ China, ${ }^{2}$ Department of Bioengineering, School of Minerals Processing and Bioengineering, Central South University, \\ Changsha, China, ${ }^{3}$ Laboratory for Marine Biology and Biotechnology, Qingdao National Laboratory forMarine Science and \\ Technology, Qingdao, China
}

Sulfobacillus acidophilus TPY, isolated from a hydrothermal vent in the Pacific Ocean, is a moderately thermoacidophilic Gram-positive bacterium that can oxidize ferrous iron or sulfur compounds to obtain energy. In this study, comparative transcriptomic analyses of S. acidophilus TPY were performed under different redox conditions. Based on these results, pathways involved in sulfur metabolism were proposed. Additional evidence was obtained by analyzing mRNA abundance of selected genes involved in the sulfur metabolism of sulfur oxygenase reductase (SOR)-overexpressed S. acidophilus TPY recombinant under different redox conditions. Comparative transcriptomic analyses of S. acidophilus TPY cultured in the presence of ferrous sulfate $\left(\mathrm{FeSO}_{4}\right)$ or elemental sulfur $\left(S^{0}\right)$ were employed to detect differentially transcribed genes and operons involved in sulfur metabolism. The mRNA abundances of genes involved in sulfur metabolism decreased in cultures containing elemental sulfur, as opposed to cultures in which $\mathrm{FeSO}_{4}$ was present where an increase in the expression of sulfur metabolism genes, particularly sulfite reductase (SiR) involved in the dissimilatory sulfate reduction, was observed. SOR, whose mRNA abundance increased in $S^{0}$ culture, may play an important role in the initial sulfur oxidation. In order to confirm the pathways, SOR overexpression in S. acidophilus TPY and subsequent mRNA abundance analysis of sulfur metabolism-related genes were carried out. Conjugation-based transformation of pTrc99A derived plasmid from heterotrophic E. coli to facultative autotrophic S. acidophilus TPY was developed in this study. Transconjugation between E. coli and S. acidophilus was performed on modified solid 2:2 medium at $\mathrm{pH} 4.8$ and $37^{\circ} \mathrm{C}$ for $72 \mathrm{~h}$. The SOR-overexpressed recombinant S. acidophilus TPY-SOR had a $\mathrm{SO}_{4}^{2-}$-accumulation increase, higher oxidation/ reduction potentials (ORPs) and lower pH compared with the wild type strain in the late growth stage of $S^{0}$ culture condition. The transcript level of sor gene in the recombinant strain 
increased in both $\mathrm{S}^{0}$ and $\mathrm{FeSO}_{4}$ culture conditions, which influenced the transcription of other genes in the proposed sulfur metabolism pathways. Overall, these results expand our understanding of sulfur metabolism within the Sulfobacillus genus and provide a successful gene-manipulation method.

Keywords: sulfur metabolism, Sulfobacillus acidophilus TPY, moderate thermoacidophile, transcriptomic analysis, SOR

\section{INTRODUCTION}

Bioleaching is the extraction of metals from their ores through the use of acidophilic chemolithotrophic microorganisms (Johnson et al., 2012). The industrial application of bioleaching microorganisms to recover metals from minerals has been wellestablished (Torma, 1983; Acevedo, 2000; Suzuki, 2001; Rawlings, 2002; Olson et al., 2003). The bioleaching microorganisms have several physiological features in common (Brune and Bayer, 2012). They are all chemolithoautotrophic and are able to use ferrous iron, elemental sulfur or reduced inorganic sulfur compounds (RISCs) as electron donors. According to the temperature at which they grow, bioleaching bacteria can be separated into mesophiles, moderate thermophiles, and thermophiles. Mesophilic microorganisms have been applied successfully for the bioleaching of gold, copper, zinc, and uranium (Brierley and Brierley, 2001; Merroun et al., 2003; Rawlings et al., 2003). However, the rate of bioleaching is limited, partially due to the fact that the bioleaching microorganisms cannot adapt to the complicated leaching conditions such as high concentrations of heavy metals and high temperature. Many researchers have studied the use of thermophilic instead of mesophilic microorganisms to improve the bioleaching rate (Brierley, 1990). However, the majority of extreme thermophiles growing above $60^{\circ} \mathrm{C}$ are classified as archaea, which always lack typical cell wall and cannot survive in high pulp density of heavy metals due to strong stirring shear (Rawlings, 2002; Rawlings et al., 2003). Leaching sulfide mines with Grampositive moderately thermophilic bacteria not only dramatically improves the bioleaching rate but also avoids inhibition by high concentration of heavy metals during bioleaching (Robertson et al., 2002; Zhou et al., 2009). Therefore, compared with mesophilic microorganisms and extreme thermophilic microorganisms, the moderately thermophilic microorganisms may offer some advantages in industrial applications of bioleaching (Brierley and Brierley, 2001; Robertson et al., 2002; Zhou et al., 2009). The genus Sulfobacillus are moderately thermophilic $\left(40^{\circ}-60^{\circ} \mathrm{C}\right)$, endospore-forming, Gram-positive bacteria that have been isolated from heaps of mineral waste and biomining operations. These bacteria are able

Abbreviations: SQR, sulfide quinone reductase; TQR, thiosulfate quinone reductase; TetH, tetrathionate reductase; TST, thiosulfate sulfur transferase (rhodanese); HDR, heterodisulfide reductase; APS reductase, adenosine phosphosulfate reductase; SAT, sulfate adenylate transferase (sulfate adenylyltransferase, ATP sulfurylase); SiR, sulfite reductase; Ttr, tetrathionate reductase; SOR, sulfur oxygenase reductase; Psr, polysulfide reductase; ORP, oxidation/ reduction potential; RISCs, reduced inorganic sulfur compounds; LB, Luria-Bertani; RPKM, reads per kb per million reads; FDR, false discovery rate; PVDF, polyvinylidene difluoride; $\mathrm{QH}_{2}$, quinone; $\mathrm{SRB}$, sulfate reducing bacteria. to grow autotrophically or heterotrophically. When growing autotrophically, they use ferrous iron, RISCs, or sulfide minerals as electron donors (Norris et al., 1996).

Bioleaching is based upon biological oxidation of iron and RISCs. The model for iron and RISCs oxidation and electron transport has been described in detail in the mesophilic bacterium Acidithiobacillus ferrooxidans ATCC 23270 and the extreme thermophilic archaeon Metallosphaera sedula DSM 5348 (Auernik et al., 2008; Valdes et al., 2008; Quatrini et al., 2009). The oxidation and electron transfer pathways for RISCs are more complex than those for iron, making their prediction, and elucidation more difficult. Due to the difficulties in developing genetic techniques in acidophiles, a large proportion of the hypotheses regarding RISCs metabolic pathways in these prokaryotes are based on systems biology (Dopson and Johnson, 2012). RISCs oxidation pathways in A. ferrooxidans ATCC 23270 are predicted to involve various enzymes, enzyme complexes, and a number of electron carriers located in different cellular compartments (Quatrini et al., 2009). A model of sulfur oxidation in A. ferrooxidans ATCC 23270 was proposed, in which electrons from oxidation of RISCs are transferred via the quinol pool $\left(\mathrm{QH}_{2}\right)$ to terminal oxidases to produce ATP, or to NADH complex I to generate $\mathrm{NAD}(\mathrm{P}) \mathrm{H}$, coupling RISCs oxidation with the generation of energy or reducing power (Quatrini et al., 2009). An integrated sulfur oxidation model that includes various sulfur oxidation pathways was proposed in A. caldus, a Gramnegative, acidophilic, obligately chemolithotrophic, moderately thermophilic bacterium (Mangold et al., 2011; Chen et al., 2012). Recently, the sulfur oxidation model of Sulfobacillus thermosulfidooxidans was proposed by two independent works via comparative genome analysis (Guo et al., 2014; Justice et al., 2014). Compared with data available for Gram-negative A. ferrooxidans and A. caldus and Gram-positive Sulfobacillus thermosulfidooxidans, to the best of our knowledge, little is known about RISCs oxidation and electron transport mechanisms in moderately thermophilic, Gram-positive $S$. acidophilus. The complexity of the sulfur metabolism system of $S$. acidophilus, as well as the lack of genetic manipulation methods for construction of mutants, represent considerable obstacles to investigation of mechanisms of $S$. acidophilus sulfur metabolism.

Until now, genetic modification of bioleaching microorganisms has been limited, in part, by technical difficulties associated with growing and manipulating these bacteria and, in part, because of public sensitivity to the use of genetically modified organisms (Rawlings, 2002). Genetic transfer between E. coli and Gram-negative A. ferrooxidans was first reported by Peng et al. (1994). Much effort has been made on the transformation of plasmid to Sulfobacilli, but no transformant 
was obtained (Joubert, 2008). To date, little progress has been made toward the development of genetic systems for the genus Sulfobacillus.

In the present study, in order to understand the sulfur metabolism of $S$. acidophilus TPY facilitating its use in bioleaching of minerals in the future, comparative transcriptomic analyses were carried out in the presence of ferrous sulfate $\left(\mathrm{FeSO}_{4}\right)$ or element sulfur $\left(\mathrm{S}^{0}\right)$ to gain global insights into the sulfur metabolism pathways and electron transport in $S$. acidophilus TPY. Then, the huge differences in culture conditions between heterotrophic $E$. coli and facultative autotrophic S. acidophilus TPY was overcome. Conjugation based transformation of plasmid to S. acidophilus TPY was also developed in this study. Further, the sulfur metabolism pathways were proposed and confirmed by pathway validation of an SOR-overexpressing S. acidophilus TPY recombinant. This is the first attempt to characterize the sulfur metabolism pathways of Gram-positive S. acidophilus and also the first report of genetic manipulation of the Gram-positive moderate thermoacidophile.

\section{MATERIALS AND METHODS}

\section{Bacterial Strains and Growth Conditions}

Bacterial strains and plasmids used in this study are listed in Supplementary Table 1. S. acidophilus TPY was isolated from a hydrothermal vent in the Pacific Ocean $\left(12^{\circ} 42^{\prime} 29^{\prime \prime} \mathrm{N}, 104^{\circ} 02^{\prime} 01^{\prime \prime}\right.$ W; water depth, $3083 \mathrm{~m}$; Li et al., 2011). It had been deposited in the China Center for Type Culture Collection (CCTCC) with accession number CCTCC M 2010203 (Li et al., 2011). It is a Gram positive bacterium and $0.3 \sim 0.5 \times 1 \sim 3 \mu \mathrm{m}$ in shape. This strain has the ability to oxidize elemental sulfur and ferrous ion as electron donors. It was grown aerobically on SA medium composed of $3 \mathrm{~g} / \mathrm{L}\left(\mathrm{NH}_{4}\right)_{2} \mathrm{SO}_{4}, 0.5 \mathrm{~g} / \mathrm{L} \mathrm{K} \mathrm{HPO}_{4}, 0.5 \mathrm{~g} / \mathrm{L}$ $\mathrm{MgSO}_{4}, 0.1 \mathrm{~g} / \mathrm{L} \mathrm{KCl}, 0.01 \mathrm{~g} / \mathrm{L} \mathrm{Ca}\left(\mathrm{NO}_{3}\right)_{2}, 0.2 \mathrm{~g} / \mathrm{L}$ yeast extract, and $13.9 \mathrm{~g} / \mathrm{L} \mathrm{FeSO}_{4} 7 \mathrm{H}_{2} \mathrm{O}$ or $1 \%$ (wt/vol) elemental sulfur as the energy source. The initial $\mathrm{pH}$ of the medium was adjusted to 1.8 with $2 \mathrm{M} \mathrm{H}_{2} \mathrm{SO}_{4}$. Cultivation was carried out in $250 \mathrm{~mL}$ flasks containing $100 \mathrm{~mL} \mathrm{SA}$ medium on a shaker at $180 \mathrm{rpm}$ and $50^{\circ} \mathrm{C}$. Escherichia coli strain JM109 was used as the host for plasmid construction, and E. coli S17-1 (Simon et al., 1983) as vector donor in conjugation. The E. coli strains were grown at $37^{\circ} \mathrm{C}$ in Luria-Bertani (LB) medium or on LB agar plates supplemented with $100 \mu \mathrm{g} / \mathrm{mL}$ ampicillin, if necessary.

\section{RNA Purification and RNA-Seq}

$S$. acidophilus TPY was cultured in the presence of ferrous sulfate or elemental sulfur as the energy source. Cells of $100 \mathrm{~mL}$ culture in the late exponential phase of growth, $24 \mathrm{~h}$ in ferrous sulfate and 3 days in elemental sulfur culture, were harvested by centrifugation at $6000 \times \mathrm{g}$ and $4^{\circ} \mathrm{C}$ and then washed three times with diluted $\mathrm{H}_{2} \mathrm{SO}_{4}, \mathrm{pH} 2.0$ (Supplementary Figure 1). The centrifugation precipitates of the cultures and the diluted $\mathrm{H}_{2} \mathrm{SO}_{4}$ were both placed on ice. Total RNA was isolated from cells using the Trizol Reagent (Invitrogen, Carlsbad, CA, USA) according to the manufacturer's instructions. Only one biological replicate was used in the preparation of RNA samples from each
$\mathrm{FeSO}_{4}$ and $\mathrm{S}^{0}$ cultures. Residual genomic DNA was digested with RNase-free DNase I (TaKaRa, Shiga, Japan). The integrity of each RNA sample was assessed by electrophoresis through a $1.2 \%$ agarose gel in $90 \mathrm{mM}$ Tris-boric acid containing $2 \mathrm{mM}$ EDTA (TBE). RNA concentration and purity were determined spectrophotometrically by measuring $A_{260}$ and $A_{260} / A_{280}$ ratio. RNA-Seq and subsequent bioinformatics analysis were carried out by Beijing Genomics Institute (BGI) at Shenzhen, China (Liu et al., 2015). The mRNA purification and fragmentation, double-stranded cDNA synthesis, RNA-seq library preparation were carried out as described previously (Qin et al., 2014). The Illumina $\mathrm{HiSeq}^{\mathrm{TM}} 2000$ platform was applied for the sequencing (Liu et al., 2015). Reads on which all following analysis are based were collected from sequence data passing BGI's quality control. Sequencing quality assessment including alignment statistics, sequencing randomness assessment and distribution of reads in reference genome ( $S$. acidophilus TPY, GenBank accession: CP002901) were carried out (Li et al., 2009). Reads were mapped to reference genome using SOAP2 (Li et al., 2009). The RNA-Seq reads have been deposited in GenBank with accession number SRP055734.

\section{Identification of Differentially Transcribed Genes}

Differentially transcribed genes were identified using a rigorous algorithm developed by BGI based on the method described previously (Audic and Claverie, 1997). The calculation of unigene transcription uses the RPKM (reads per kb per million reads) method (Mortazavi et al., 2008). The calculated gene transcription profile can be used to directly compare gene transcription levels between samples. Genes with $\log _{2}$ (ratio $\mathrm{RPKM}$ ) values $>2.0$ or $<-2.0$ were considered to be increased or decreased, respectively. In addition, those genes with false discovery rate (FDR) $<0.001$ in the samples were also included.

\section{Total RNA Extraction and RT-qPCR Assays}

In order to verify the transcription levels of genes involved in the sulfur metabolism pathways, RT-qPCR assays were carried out. S. acidophilus TPY cultivation and total RNA extraction were conducted as described above for RNA-Seq. Reverse transcription was performed using cDNA synthesis kit (M-MLV Version, TaKaRa) according to the manufacturer's instructions. Transcription levels of representative genes in the sulfur metabolism pathways of $S$. acidophilus TPY were characterized using an ABI PRISM 7500 Real-Time System with a SYBR Green-based assay. Primers used to amplify representative genes of the sulfur metabolism pathways and the 16S rRNA gene, which served as an internal control, are shown in Supplementary Table 2. Total RNA was extracted from three independent cultures with ferrous sulfate or elemental sulfur, respectively. RTqPCR quantification was performed three times for each RNA sample. Therefore, transcript levels were measured in triplicate for each RNA isolate. The Reverse transcription reaction mixture $(20 \mu \mathrm{L})$ in a $200 \mu \mathrm{L}$ tube contained $1 \mathrm{mg}$ Total RNA, $2 \mu \mathrm{L}$ random primers (Promega, $10 \mu \mathrm{M}$ ), $4 \mu \mathrm{L} 5 \times \mathrm{M}-\mathrm{MLV}$ Buffer, $1 \mu \mathrm{L}$ dNTP Mixture, $0.5 \mu \mathrm{L}$ RNase Inhibitor (40 U/ $\mu \mathrm{L}), 0.5$ 
$\mu \mathrm{L}$ Reverse Transcriptase M-MLV (RNase H-; $200 \mathrm{U} \mu \mathrm{L}$ ) and $12 \mu \mathrm{L}$ RNase Free water. The reaction was performed at $42^{\circ} \mathrm{C}$ for $1 \mathrm{~h}$ and then at $70^{\circ} \mathrm{C}$ to end the reaction. Each RT-qPCR mixture $(20 \mu \mathrm{L})$ in a $200 \mu \mathrm{L}$ tube contained $10 \mu \mathrm{L}$ SYBR $^{\circledR}$ Premix Ex Taq ${ }^{\mathrm{TM}}$ (Taq DNA polymerase, dNTPs, $\mathrm{MgCl}_{2}$, SYBR Green I dye, $2 \times), 0.4 \mu \mathrm{L}$ PCR Forward Primer $(10 \mu \mathrm{M}), 0.4$ $\mu \mathrm{L}$ PCR Reverse Primer $(10 \mu \mathrm{M}), 1.0 \mu \mathrm{L}$ SS DNA template, and $8.2 \mu \mathrm{L} \mathrm{H} \mathrm{H}_{2} \mathrm{O}$. The RT-qPCR reaction was performed with the following cycling condition: (1) $50^{\circ} \mathrm{C}$ for $2 \mathrm{~min}$; (2) $95^{\circ} \mathrm{C}$ for $3 \mathrm{~min}$; (3) 40 cycles of $95^{\circ} \mathrm{C}$ for $20 \mathrm{~s}$ and $56^{\circ} \mathrm{C}$ for $40 \mathrm{~s}$ and $72^{\circ} \mathrm{C}$ for $45 \mathrm{~s}$; (4) $4^{\circ} \mathrm{C}$ hold with data collection at each annealing step. The $16 \mathrm{~S}$ rDNA was used as the reference gene for normalization. The relative transcription was calculated using the comparative $\Delta \Delta$ CT method (Livak and Schmittgen, 2001). Levels of transcripts in S. acidophilus TPY cultivated in $\mathrm{FeSO}_{4}$ are expressed as $\mathrm{n}$-fold relative to that of the same gene in $S$. acidophilus TPY cultured in $S^{0}$.

\section{Construction of Sulfur Oxygenase Reductase (SOR) Expression Plasmid}

As $S$. acidophilus TPY is a Gram-positive bacterium, the Bacillus E. coli shuttle vector pTrc99A (Amann et al., 1988) was used to construct the expression plasmid pTrc99A_sor_oriT. Two pairs of primers were designed to amplify the sor gene encoding the sulfur oxygenase reductase (SOR) from $S$. acidophilus TPY genomic DNA and oriT fragment of plasmid pEx18Tc (Hoang et al., 1998), respectively (Supplementary Table 2). The amplified sor fragment was purified and cloned into the EcoRI/BamHI site of pTrc99A (Amann et al., 1988) in frame with a $6 \times$ His tag. The resulting plasmid was named pTrc99A_sor. The amplified oriT fragment was then cloned into the BamHI/HindIII site of pTrc99A_sor to form expression vector pTrc99A_sor_oriT (Supplementary Figure 2). E. coli S17-1 (Simon et al., 1983) was transformed with the plasmid pTrc99A_sor_oriT for transconjugation, which was carried out using S. acidophilus TPY as the recipient bacterium.

\section{Transconjugation between $E$. coli and S. acidophilus}

Modified solid 2:2 medium was used as transconjugation medium and prepared in three parts (Peng et al., 1994). $\mathrm{Na}_{2} \mathrm{~S}_{2} \mathrm{O}_{3} \cdot 5 \mathrm{H}_{2} \mathrm{O}\left(2 \mathrm{~g}\right.$ ) was added to $20 \mathrm{~mL}$ of $\mathrm{H}_{2} \mathrm{O}$ (solution A); $\left(\mathrm{NH}_{4}\right)_{2} \mathrm{SO}_{4}(4.5 \mathrm{~g}), \mathrm{KCl}(0.15 \mathrm{~g}), \mathrm{MgSO}_{4} \cdot 7 \mathrm{H}_{2} \mathrm{O}(0.75 \mathrm{~g})$ and yeast extract $(0.5 \mathrm{~g})$ were dissolved in $500 \mathrm{~mL}$ of $\mathrm{H}_{2} \mathrm{O}$ and then adjusted to $\mathrm{pH} 4.8$ with $2 \mathrm{M} \mathrm{H}_{2} \mathrm{SO}_{4}$ (solution B); Gellan Gum (10 g; Sigma-Aldrich Corporation, USA) was added to $480 \mathrm{~mL}$ of $\mathrm{H}_{2} \mathrm{O}$ (solution $\mathrm{C}$ ). Solutions $\mathrm{A}$ was filter sterilized, while solutions $\mathrm{B}$ and $\mathrm{C}$ were autoclaved. Solutions $\mathrm{A}, \mathrm{B}$, and $\mathrm{C}$ were mixed together when solutions $\mathrm{B}$ and $\mathrm{C}$ were cooled to $80^{\circ} \mathrm{C}$. The final $\mathrm{pH}$ of the medium was 4.8 . About $30 \mathrm{~mL}$ of modified solid 2:2 medium was poured into each $9 \mathrm{~cm}$-diameter plate. Transconjugation of plasmid pTrc99A_sor_oriT from E. coli S171 to $S$. acidophilus TPY was conducted by filter mating. Donor cells were harvested by centrifugation at the late exponential growth phase; recipient cells were harvested at the stationary phase. Iron or sulfur precipitates were removed by low-speed centrifugation $(100 \times \mathrm{g})$ from SA medium liquid culture. Both the donor and recipient cells were washed three times with elution solution $\left(4.5 \mathrm{~g} / \mathrm{L}\left(\mathrm{NH}_{4}\right)_{2} \mathrm{SO}_{4}, 0.15 \mathrm{~g} / \mathrm{L} \mathrm{KCl}, 0.75 \mathrm{~g} / \mathrm{L}\right.$ $\left.\mathrm{MgSO}_{4} \cdot 7 \mathrm{H}_{2} \mathrm{O}, \mathrm{pH} 4.8\right)$ and then mixed at a donor-to-recipient ratio of 1:1. Cell suspension $(100 \mu \mathrm{L})$ was then transferred to a filter membrane $(0.45 \mu \mathrm{m}$ pore size; $25 \mathrm{~mm}$ diameter) placed on the modified solid $2: 2$ medium. After incubation at $37^{\circ} \mathrm{C}$ for $72 \mathrm{~h}$, the bacterial lawn on the filter was washed with $3.0 \mathrm{~mL}$ of elution solution. The bacterial eluent was diluted and spread on the modified solid 2:2 medium selection plates with $100 \mu \mathrm{g} / \mathrm{mL}$ of ampicillin added to select transconjugants at $50^{\circ} \mathrm{C}$.

\section{Western Blot Analysis of Overexpressed SOR}

S. acidophilus TPY and recombinant S. acidophilus TPY-SOR cells were grown to the late exponential phase after cultivation in 250 $\mathrm{mL}$ flasks containing $100 \mathrm{~mL}$ of SA medium in the presence of $\mathrm{FeSO}_{4}$ as the energy source. Cells were harvested from $50 \mathrm{~mL}$ of SA medium by centrifugation at $6000 \times \mathrm{g}$ at $4^{\circ} \mathrm{C}$, washed three times with diluted $\mathrm{H}_{2} \mathrm{SO}_{4}, \mathrm{pH} 2.0$, resuspended in $1 \mathrm{~mL}$ PBS buffer ( $\mathrm{pH} 7.4)$. Then, $20 \mu \mathrm{L}$ of the cell suspension was mixed with $80 \mu \mathrm{L} 5 \times$ SDS-PAGE loading buffer and boiled at $100^{\circ} \mathrm{C}$ for $10 \mathrm{~min}$. The total protein extracts sample $(10 \mu \mathrm{L})$ from the S. acidophilus TPY and recombinant S. acidophilus TPYSOR were separated by SDS-PAGE through 15\% acrylamide gels, and electrotransferred onto polyvinylidene difluoride (PVDF) membranes using standard methods. The PVDF membrane was then washed with Tris-buffered saline containing $0.1 \%$ Tween 20 (TBST) twice for $5 \mathrm{~min}$ each. The membrane was then incubated in anti-6 $\times$ His tag monoclonal antibody (Roche) as the primary antibody and then horseradish peroxidase-conjugated polyclonal rabbit anti-mouse IgG (Thermo Scientific, Waltham, MA, USA) as the secondary antibody. Immunoreactive proteins were detected using NBT/BCIP (Thermo Scientific) as substrate according to the manufacturer's recommendations.

\section{Characterization of Recombinant Strain S. acidophilus TPY-SOR}

Equal amounts of inoculum $(5 \%, \mathrm{v} / \mathrm{v})$ of S. acidophilus TPY and recombinant $S$. acidophilus TPY-SOR were inoculated into $250 \mathrm{~mL}$ flasks containing $100 \mathrm{~mL}$ of SA medium with $1 \%(\mathrm{w} / \mathrm{v})$ elemental sulfur as energy source. Flasks were incubated at $50^{\circ} \mathrm{C}$ and $200 \mathrm{rpm}$ on a rotary shaker for 11 days. Variations in ORPs, $\mathrm{pH}$, and $\mathrm{SO}_{4}^{2-}$ concentration of the cultures were measured using an ORP meter, $\mathrm{pH}$ meter, and $\mathrm{BaSO}_{4}$ turbidimetry (Agterdenbos and Martinius, 1964). S. acidophilus TPY and S. acidophilus TPY-SOR were compared in the three parameters above when they were cultivated under the same conditions. The S. acidophilus TPY and S. acidophilus TPY-SOR cultivation were done in triplicate and the results are shown as the mean \pm SD. Meanwhile, S. acidophilus TPY and S. acidophilus TPY-SOR cells were grown to the late exponential phase after inoculation in $\mathrm{SA}$ medium in the presence of $\mathrm{FeSO}_{4}$ or $\mathrm{S}^{0}$ as the energy source. RT-qPCR was carried out to analyse levels of transcripts of representative genes in the sulfur metabolism pathways in 
the recombinant $S$. acidophilus TPY-SOR under $\mathrm{FeSO}_{4}$ or $\mathrm{S}^{0}$ cultivation condition, respectively, using the wild type strain $S$. acidophilus TPY as control.

\section{RESULTS}

\section{General Features of the Transcriptional Profiles Generated by RNA-Seq and Sulfur Metabolism Pathways of S. acidophilus TPY}

Comparative analysis of the transcribed gene profiles has provided extensive biological information about the response of S. acidophilus TPY grown in the presence of $\mathrm{S}^{0}$ or $\mathrm{FeSO}_{4}$ on a genomic scale. Using statistical criteria described previously, a $2.0 \log _{2}$ (ratio RPKM) of median cutoff was considered as differential gene transcription under the two growth conditions (Mortazavi et al., 2008). A total of 841 genes showed a differential transcription profile, of which 507 were increased (by up to 14.4-fold) and 334 were decreased (by up to 13.5fold) in $\mathrm{FeSO}_{4}$ compared to $\mathrm{S}^{0}$ (Supplementary Table 3). Genes exhibiting differential transcription were annotated by Gene Ontology and KEGG and were found to be mostly associated with unknown functions, energy metabolism and central intermediary processes. Genes and operons involved in the sulfur metabolism pathways were analyzed in further detail according to their differential mRNA abundance levels (Table 1). Quantitative reverse transcription PCR analysis of representative genes involved in the sulfur metabolism confirmed the transcriptome results (Table 1). The RNA samples analyzed for the two methods were different, strongly suggesting that the biological observations were reproducible. Reactions and related genes or operons involved in the sulfur metabolism of $S$. acidophilus TPY were listed in Table 2. Based on these reactions, we proposed the $S$. acidophilus TPY sulfur metabolism pathways with redox cycles shown in Figure 1.

\section{Genes in the Sulfate Reducing Operon with mRNA Abundance Increased under Conditions of Growth in $\mathrm{FeSO}_{4}$}

It can be clearly seen from Table 1 that genes in the sulfate reducing operon were increased by as much as 14.34-fold under conditions of growth in $\mathrm{FeSO}_{4}$. Reduction of sulfate to sulfide can be divided into two steps: (i) reduction of sulfate to sulfite (Table 2, reactions 7 and 8 ), which is associated with conversion of ATP to AMP and pyrophosphate via sulfate adenylyltransferase encoded by sat (TPY_2303, 8.79fold increase in $\mathrm{FeSO}_{4}$ ) and adenosine phosphosulfate (APS) reductase encoded by cysH (TPY_2304, 8.27-fold increase in $\mathrm{FeSO}_{4}$ ), and (ii) the six-electron reduction of sulfite to sulfide, which is carried out by the sulfite reductase ( $\mathrm{SiR}$, Table 2, reaction 9) encoded by cysI (TPY_2305, 9.03-fold increase in $\mathrm{FeSO}_{4}$, Table 1). The other genes (TPY_2299-2302) in the sulfate reducing operon that encode enzymes involved in the synthesis of siroheme were also increased 5.78- to 14.34-fold under conditions of growth in $\mathrm{FeSO}_{4}$. Siroheme is a heme-like prosthetic group used by some enzymes to accomplish the sixelectron reduction of sulfur (Murphy et al., 1974). It plays a major role in the sulfur metabolism pathways by converting sulfite to a biologically useful sulfide (Thomas and Surdin-Kerjan, 1997).

\section{Other Genes and Operons with mRNA Abundance Increased under Conditions of Growth in $\mathrm{FeSO}_{4}$}

Sulfide generated under $\mathrm{SiR}$ catalysis in the $\mathrm{FeSO}_{4}$-containing medium would be oxidized into polysulfide by the mRNA abundance increased sulfide-quinone oxidoreductase (SQR; Table 2, reaction 1) encoded by sqr (TPY_3704, 1.56-fold increase in $\mathrm{FeSO}_{4}$, Table 1). Sulfide would also be used during the synthesis of L-cysteine (Zeghouf et al., 2000). As a result, the cysteine synthase A encoding gene cysK (TPY_0363) involved in the synthesis of L-cysteine was also increased 4.12-fold under $\mathrm{FeSO}_{4}$ growth condition. However, the cysteine desulfurase encoding gene sufS (TPY_3319) was decreased 2.58-fold under $\mathrm{FeSO}_{4}$ growth condition. Cysteine desulfurase decomposes Lcysteine to L-alanine and sulfane sulfur via the formation of an enzyme bound persulfide intermediate (Mihara and Esaki, 2002). In addition to producing sulfide, another product of sulfite would be thiosulfate in the presence of $S^{0}$ by an abiotic process. In $\mathrm{FeSO}_{4}$-containing growth medium, a high mRNA abundance of the thiosulfate/quinone oxidoreductase (TQR) complex operon was observed, which might be due to the deduced accumulation of thiosulfate. TQR, encoded by $\operatorname{doxDA}$ (TPY_2169, 6.08fold increase in $\mathrm{FeSO}_{4}$, Table 1), catalyzed the conversion of thiosulfate into tetrathionate, and conversely, tetrathionate would be reduced by tetrathionate reductase (Ttr), encoded by ttrA (TPY_3701, 6.54-fold increase in $\mathrm{FeSO}_{4}$ ), ttrB (TPY_3699, 9.06-fold increase in $\mathrm{FeSO}_{4}$ ), $\operatorname{ttrC}$ (TPY_3700, 7.57-fold increase in $\mathrm{FeSO}_{4}$ ) and ttrD (TPY_3702, 4.60-fold increase in $\mathrm{FeSO}_{4}$; Hensel et al., 1999). Also embedded in the tetrathionate reductase operon were tatA (TPY_3698, 11.6-fold increase in $\mathrm{FeSO}_{4}$ ) and tatC (TPY_3703, 4.94-fold increase in $\mathrm{FeSO}_{4}$ ), which encode twin arginine-targeting protein translocase and may be involved in transportion of $\operatorname{Ttr} \mathrm{B}$ and $\mathrm{Ttr} \mathrm{A}$ across membranes (Berks et al., 2000). Tetrathionate can also be hydrolyzed by tetrathionate hydrolase (TetH) to thiosulfate, sulfate, and $\mathrm{S}^{0}$. TetH is encoded by tetH (TPY_0895), which was transcribed at almost identical levels in the presence of $S^{0}$ and $\mathrm{FeSO}_{4}$. Thiosulfate sulfur transferase (TST), encoded by tusA (TPY_0056), was increased 4.75 -fold in $\mathrm{FeSO}_{4}$. The thiol proteins (RSH) can be used as sulfur atom acceptors for the catalysis of thiosulfate to sulfite by TST, producing sulfane sulfate (RSSH) which is the substrate of the heterodisulfide reductase complex (HDR; Chen et al., 2012). Thus, RSH obtains a sulfur atom to form RSSH catalyzed by TST, and then RSSH is oxidized by HDR to regenerate RSH (Table 2, reactions 5 and 6). With growth in $\mathrm{FeSO}_{4}$, mRNA abundances of all six $h d r$ genes were increased up to 3.0-fold compared with growth in $S^{0}$ (Table 1). Besides, the petII operon, which encodes an important component of the electron transfer system in $A$. ferrooxidans ATCC 23270 (Valdes et al., 2008; Quatrini et al., 2009), was not found in the S. acidophilus TPY genome. It has been presumed that the petI operon participates not only in the electron transfer of $\mathrm{Fe}^{2+}$ oxidation but also that of RISCs oxidation (Table 1). 
TABLE 1 | Gene clusters involved in the sulfur metabolism and electron transfer of Sulfobacillus acidophilus TPY.

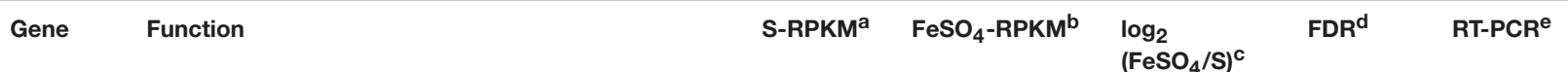

\section{PET I OPERON}

TPY 3079 PetC-1

Cytochrome $c$ subunit of the bc complex

471.4

6028.6

3.68

$(0$

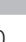

$4.92 \pm 0.22$

TPY_3080 petB-1

Cytochrome $b$ subunit of the bc complex

150.2

4771.0

4.99

$3.1 \times 10^{-13}$

TPY 3081

Uncharacterized protein required for cytochrome oxidase

191.8

136.5

$-0.49$

$2.94 \times 10^{-14}$

\section{CYTOCHROME bd UBIQUINOL OXIDASE}

\begin{tabular}{|c|c|c|c|c|c|c|c|}
\hline TPY_1817 & cydA & Cytochrome bd ubiquinol oxidase subunit I & 148.8 & 99.4 & -0.58 & $2.09 \times 10^{-21}$ & \\
\hline TPY_1818 & cydB & Cytochrome d ubiquinol oxidase, subunit II & 155.1 & 83.3 & -0.90 & $2.13 \times 10^{-33}$ & \\
\hline TPY_3557 & & & 17.4 & 7.7 & -1.17 & $8.05 \times 10^{-7}$ & \\
\hline \multicolumn{8}{|c|}{ CYTOCHROME $b_{3}$ UBIQUINOL OXIDASE } \\
\hline TPY_0365 & суов & Cytochrome o ubiquinol oxidase, subunit I & 741.3 & 160.3 & -2.21 & 0 & \\
\hline TPY_0364 & CyOA & Cytochrome o ubiquinol oxidase, subunit II & 527.7 & 78.0 & -2.76 & 0 & $0.14 \pm 0.02$ \\
\hline \multicolumn{8}{|c|}{ SULFATE REDUCING OPERON } \\
\hline TPY_2305 & cysl & Sulfite reductase (NADPH) hemoprotein beta-component & 4.8 & 2522.7 & 9.03 & $1.36 \times 10^{-13}$ & $2.31 \pm 0.24$ \\
\hline TPY_2301 & cysG & Uroporphyrin-III C-methyltransferase & 5.5 & 824.2 & 7.21 & $3.53 \times 10^{-11}$ & \\
\hline TPY_2300 & ahpC & Peroxiredoxin (alkyl hydroperoxide reductase subunit C) & 35.0 & 1915.0 & 5.78 & $6.4 \times 10^{-13}$ & \\
\hline TPY_2299 & & Hypothetical protein new & $0^{f}$ & 20.7 & 14.34 & $4.25 \times 10^{-6}$ & \\
\hline \multicolumn{8}{|c|}{ THIOSULFATE-QUINONE OXIDOREDUCTASE COMPLEX OPERON } \\
\hline TPY_2169 & $\operatorname{dox} D A$ & Thiosulfate-quinone oxidoreductase small subunit DoxD & 1.5 & 99.3 & 6.08 & $3.07 \times 10^{-5}$ & $2.22 \pm 0.20$ \\
\hline TPY_2170 & & Periplasmic solute-binding protein, putative & 3.7 & 293.9 & 6.30 & $2.45 \times 10^{-7}$ & \\
\hline TPY_2171 & & $\begin{array}{l}\text { Tat (twin-arginine translocation) pathway signal sequence } \\
\text { domain protein }\end{array}$ & 1.9 & 165.1 & 6.41 & $1.79 \times 10^{-4}$ & \\
\hline TPY_2172 & & C4-dicarboxylate transporter/malic acid transport protein & 2.7 & 35.4 & 3.71 & $8.22 \times 10^{-6}$ & \\
\hline
\end{tabular}

\section{TETRATHIONATE HYDROLASE}

TPY 0895 tetH

Tetrathionate hydrolase

12.2

15

$\begin{array}{lll}0.30 & 0.089 & 1.34 \pm 0.15\end{array}$

\section{TETRATHIONATE REDUCTASE OPERON}

$\begin{array}{lll}\text { TPY_3698 } & \text { tatA } & \text { Sec-independent protein translocase protein TatA } \\ \text { TPY_3699 } & \text { ttrB } & \text { Tetrathionate reductase subunit B } \\ \text { TPY_3700 } & \text { ttrC } & \text { Tetrathionate reductase subunit C } \\ \text { TPY_3701 } & \text { ttrA } & \text { Molybdopterin dinucleotide-binding region } \\ \text { TPY_3702 } & \text { ttrD } & \text { Tetrathionate reductase subunit D } \\ \text { TPY_3703 } & \text { tatC } & \text { Twin arginine-targeting protein translocase TatC }\end{array}$

\section{SULFIDE-QUINONE OXIDOREDUCTASE}

TPY_3704 sqr Sulfide-quinone oxidoreductase

TPY_3731

83

\section{SULFUR OXYGENASE REDUCTASE}

\begin{tabular}{|c|c|c|c|c|c|c|c|}
\hline TPY_0405 & sor & Sulfur oxygenase reductase & 44.6 & 4.5 & -3.32 & $1.41 \times 10^{-53}$ & $0.33 \pm 0.27$ \\
\hline \multicolumn{8}{|l|}{ SoeABC } \\
\hline TPY_0113 & SoeA & $\begin{array}{l}\text { Molybdopterin oxidoreductase, molybdopterin binding } \\
\text { subunit }\end{array}$ & 319.4 & 6.8 & -5.55 & 0 & \\
\hline
\end{tabular}


TABLE 1 | Continued

\begin{tabular}{|c|c|c|c|c|c|c|c|}
\hline & Gene & Function & S-RPKMa & $\mathrm{FeSO}_{4}-\mathrm{RPKM}^{\mathrm{b}}$ & $\begin{array}{l}\log _{2} \\
\left(\mathrm{FeSO}_{4} / \mathrm{S}\right)^{\mathrm{c}}\end{array}$ & FDR $^{\mathbf{d}}$ & RT-PCR ${ }^{e}$ \\
\hline TPY_0114 & SoeB & $\begin{array}{l}\text { Molybdopterin oxidoreductase, iron-sulfur binding } \\
\text { subunit }\end{array}$ & 504.9 & 14.3 & -5.14 & 0 & \\
\hline TPY_0115 & SoeC & $\begin{array}{l}\text { Molybdopterin oxidoreductase subunit C, membrane } \\
\text { anchor subunit }\end{array}$ & 499.2 & 25.7 & -4.28 & 0 & $0.47 \pm 0.11$ \\
\hline \multicolumn{8}{|c|}{ HETERODISULFIDE REDUCTASE COMPLEX OPERON } \\
\hline TPY_3532 & $d s r E$ & Hypothetical protein & 15.3 & 121.9 & 3.00 & $3.5 \times 10^{-13}$ & \\
\hline TPY_3531 & hdrC & Heterodisulfide reductase, subunit C & 27.3 & 95.5 & 1.80 & 0 & \\
\hline TPY_3530 & $h d r B$ & Heterodisulfide reductase, subunit B & 13.0 & 46.7 & 1.84 & $2.69 \times 10^{-13}$ & \\
\hline TPY_3529 & hdrA & $\begin{array}{l}\text { Heterodisulfide reductase, subunit A, and related } \\
\text { polyferredoxins }\end{array}$ & 10.8 & 27.7 & 1.35 & $1.10 \times 10^{-12}$ & \\
\hline TPY_3528 & orf2 & Hypothetical protein & 3.3 & 11.9 & 1.84 & $3.69 \times 10^{-6}$ & \\
\hline TPY_3527 & $h d r D$ & heterodisulfide reductase subunit D & 12.8 & 36.3 & 1.50 & 0 & \\
\hline \multicolumn{8}{|c|}{ RHODANESE } \\
\hline TPY_2911 & rhd & Rhodanese-related sulfurtransferase & 766.2 & 73.8 & -3.38 & 0 & \\
\hline TPY_0056 & tus $A$ & SirA family protein, Rhodanese-related sulfurtransferase & 18.1 & 486.1 & 4.75 & $1.74 \times 10^{-11}$ & \\
\hline TPY_1113 & & & 825.8 & 172.0 & -2.26 & $\begin{array}{l}8.36 \times \\
10^{-163}\end{array}$ & \\
\hline TPY_3523 & & & 2.1 & 5.5 & 1.38 & 0.195 & \\
\hline TPY_3767 & & & 69.2 & 48.8 & -0.50 & 0.032 & \\
\hline TPY_0110 & & & 66.4 & 3.9 & -4.09 & $9.05 \times 10^{-32}$ & \\
\hline \multicolumn{8}{|l|}{ OTHERS } \\
\hline TPY_0363 & cysk & Cysteine synthase A & 87.6 & 1528.3 & 4.12 & $6.32 \times 10^{-13}$ & \\
\hline TPY_3319 & sufS & Cysteine desulfurase & 1216.4 & 203.3 & -2.58 & 0 & \\
\hline
\end{tabular}

${ }^{a} R P K M$-values of genes from S. acidophilus TPY cultured in the presence of elemental sulfur as the energy source. RPKM, reads per kb per million reads.

${ }^{b} R P K M$-values of genes from S. acidophilus TPY cultured in the presence of ferrous sulfate as the energy source.

${ }^{c}$ The $\log _{2}$ ratio of $\mathrm{FeSO}_{4}-\mathrm{RPKM} / \mathrm{S}-\mathrm{RPKM}$.

${ }^{d}$ False discovery rate.

e Levels of transcripts in S. acidophilus TPY cultivated in $\mathrm{FeSO}_{4}$ from RT-PCR are expressed as $n$-fold relative to that of S. acidoLphilus TPY cultivated in S ${ }^{\circ}$

${ }^{f}$ The RPKM-value was set as 0.001 in the calculation of log2 ratio of ( $\left.\mathrm{FeSO}_{4}-\mathrm{RPKM} / \mathrm{S}-\mathrm{RPKM}\right)$ when its value equals zero.

\section{Genes and Operons with mRNA Abundance Increased under Conditions of Growth in $\mathbf{S}^{0}$}

Although three copies of $c y d A B$ (TPY_1817-1818, TPY_18431842, and TPY_3556-3557) encode $b \bar{d}$ oxidase, only the copy TPY_1817-1818 had a high RPKM-value under conditions of growth in both $S^{0}$ and $\mathrm{FeSO}_{4}$, indicating a high level of transcription. This highly transcribed copy of $c y d A B$, together with cyoABCD (TPY_0364-0367), encoding a $b o_{3}$ oxidase, SoeABC (TPY_0113-0115) encoding molybdopterin oxidoreductase and sor (TPY_0405) encoding sulfur oxygenase reductase (SOR) were increased under conditions of growth in $S^{0}$. SOR has been found to play a central role in the cytoplasmic sulfur oxidation pathways in several acidophilic and thermophilic archaea (Kletzin et al., 2004; Ghosh and Dam, 2009). SOR is able to catalyze the disproportionation of $S^{0}$, producing sulfite, thiosulfate, and sulfide (Table 2, reaction 4). These products then follow into corresponding oxidation pathways transferring electrons to quinone $\left(\mathrm{QH}_{2}\right)$. Electrons produced from the elemental sulfur and RISCs oxidation via $\mathrm{QH}_{2}$ were transferred to the terminal oxidases $\left(b d\right.$ and $\left.b o_{3}\right)$ and the NADH complex to produce ATP and $\mathrm{NAD}(\mathrm{P}) \mathrm{H}$, respectively. When $S$. acidophilus TPY was grown in $\mathrm{S}^{0}$-containing medium, sor was induced directly by $S^{0}$ with 3.32 -fold increase. Subsequently, $c y d A B$ (TPY_1817-1818), encoding $b d$ oxidase, and $c y o A B C D$ (TPY_0364-0367), encoding a bo 3 oxidase were also increased by up to 2.76 -fold under conditions of growth in $S^{0}$. Also increased under $S^{0}$ growth conditions were SoeABC encoding genes TPY_0113, 0114, and 0115. SoeABC which consists of an $\mathrm{NrfD} /$ PsrC like membrane anchor (SoeC) and two cytoplasmic subunits: an iron-sulfur protein (SoeB) and a molybdoprotein with an N-terminal iron-sulfur cluster binding site (SoeA) was thought to be a major enzyme catalysing direct oxidation of sulfite to sulfate in the cytoplasm of Allochromatium vinosum (Dahl et al., 2013). The high mRNA abundance levels of SoeABC under $S^{0}$ growth conditions was presumed to be due to the accumulation of sulfite derived from the product of SOR.

\section{Overexpression of sor in S. acidophilus TPY}

In order to confirm the role of SOR in the sulfur metabolism pathways in S. acidophilus TPY, overexpression of sor was performed. Due to its important role in the initial oxidation of $S^{0}$ to sulfate, SOR was chosen as the target enzyme for 
TABLE 2 | Reactions of selected enzymes that require inorganic sulfur compounds.

\begin{tabular}{|c|c|c|c|c|}
\hline NO. & Reactions & Enzymes & Locus of TPY & References \\
\hline 1 & $\mathrm{n} \mathrm{HS}-+\mathrm{n}$ quinine $\rightarrow^{-} \mathrm{S}-(\mathrm{S})_{n-2}-\mathrm{S}^{-}+\mathrm{n}$ quinol & Sulfide quinone reductase (SQR) & TPY_3704, 3731 & Quatrini et al., 2009 \\
\hline 2 & $\begin{array}{l}2-\mathrm{S}_{-} \mathrm{SO}_{3}^{-}+2 \text { Ferricytochrome c } \rightarrow \\
-\mathrm{O}_{3} \mathrm{~S}-\mathrm{S}-\mathrm{S}_{-} \mathrm{SO}_{3}^{-}+2 \text { Ferrocytochrome c }\end{array}$ & Thiosulfate quinone oxidoreductase (TQR) & TPY_2169 & R00029a \\
\hline 3 & $-\mathrm{O}_{3} \mathrm{~S}-\mathrm{S}-\mathrm{S}-\mathrm{SO}_{3}^{-} \rightarrow-\mathrm{S}^{-} \mathrm{SO}_{3}^{-}+\mathrm{SO}_{4}^{2-}+\mathrm{S}^{0}$ & Tetrathionate hydrolase (TetH) & TPY_0895 & De Jong Gah et al., 1997 \\
\hline 4 & $4 \mathrm{~S}^{0}+4 \mathrm{H}_{2} \mathrm{O}+\mathrm{O}_{2} \rightarrow 2 \mathrm{H}_{2} \mathrm{~S}+2 \mathrm{HSO}_{3}^{-}+2 \mathrm{H}^{+}$ & Sulfur oxygenase reductase (SOR) & TPY_0405 & Chen et al., 2012, R07365 \\
\hline 5 & $\mathrm{RSH}+{ }^{-} \mathrm{S}_{-} \mathrm{SO}_{3}^{-} \rightarrow \mathrm{RSSH}+\mathrm{HSO}_{3}^{-}$ & $\begin{array}{l}\text { Thiosulfate sulfur transferase (TST, } \\
\text { rhodanese) }\end{array}$ & $\begin{array}{l}\text { TPY_0056, 0110, } \\
\text { 1113, 2911, 3523, } \\
3767\end{array}$ & Chen et al., 2012 \\
\hline 6 & $\mathrm{RSSH} \rightarrow \mathrm{RSH}+\mathrm{HSO}_{3}^{-}$ & Heterodisulfide reductase (HDR) & TPY_3527-3532 & Chen et al., 2012 \\
\hline 7 & $\begin{array}{l}\mathrm{AMP}+\mathrm{HSO}_{3}^{-}+\text {Glutathione disulfide }<=> \\
\text { Adenylyl sulfate }+2 \text { Glutathione }\end{array}$ & $\begin{array}{l}\text { Adenosine phosphosulfate (APS) } \\
\text { reductase }\end{array}$ & TPY_2304 & R05717 \\
\hline 8 & Adenylyl sulfate + Diphosphate $<=>$ ATP $+\mathrm{H}_{2} \mathrm{SO}_{4}$ & Sulfate adenylyltransferase (SAT) & TPY_2303 & R00529 \\
\hline 9 & $\begin{array}{l}\mathrm{HSO}_{3}^{-}+3 \mathrm{NADPH}+3 \mathrm{H}^{+} \rightarrow 3 \mathrm{NADP}+3 \mathrm{H}_{2} \mathrm{O}+ \\
\mathrm{HS}^{-}\end{array}$ & Sulfite reductase (SiR) & TPY_2305 & R00858, Zeghouf et al., 2000 \\
\hline 10 & 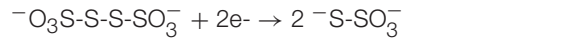 & Tetathionate reductase (Ttr) & TPY_3698-3703 & Hensel et al., 1999 \\
\hline 11 & $\mathrm{H}_{2} \mathrm{SO}_{3}+\mathrm{H}_{2} \mathrm{O} \rightarrow \mathrm{H}_{2} \mathrm{SO}_{4}+2 \mathrm{H}^{+}$ & $\begin{array}{l}\text { molybdopterin binding oxidoreductase; } \\
\text { SoeABC }\end{array}$ & $\begin{array}{l}\text { TPY_0113, 0114, } \\
0115\end{array}$ & Dahl et al., 2013, R00533 \\
\hline 12 & $\begin{array}{l}\text { O-Acetyl-L-serine }+\mathrm{H}_{2} \mathrm{~S}<=>\text { L-Cysteine }+ \\
\text { Acetate }\end{array}$ & Cysteine synthase A & TPY_0363 & R00897 \\
\hline 13 & $\begin{array}{l}\text { [Enzyme]-cysteine }+ \text { L-Cysteine }<=> \\
{[\text { Enzyme]-S-sulfanylcysteine }+ \text { L-Alanine }}\end{array}$ & Cysteine desulfurase & TPY_3319 & R07460, Mihara and Esaki, 2002 \\
\hline
\end{tabular}

${ }^{a}$ Reaction number in KEGG database (http://www.genome.jp/kegg/).

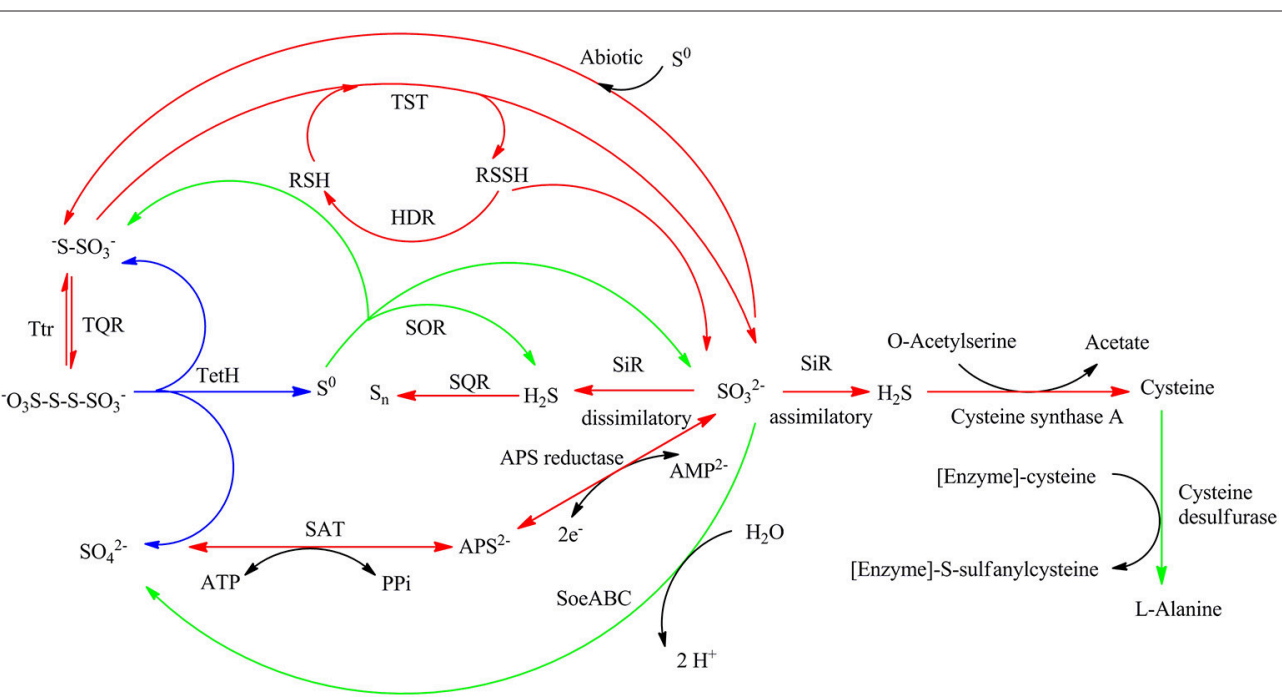

FIGURE 1 | Proposed sulfur metabolism pathways of Sulfobacillus acidophilus TPY. Arrows in red and green indicate reactions carried out by genes or operons with mRNA abundance increased under conditions of growth in $\mathrm{FeSO}_{4}$ and $\mathrm{S}^{0}$, respectively. Arrows in blue indicate reactions carried out by genes or operons with mRNA abundance almost the same under conditions of growth in $\mathrm{FeSO}_{4}$ and $\mathrm{S}^{0}$. SQR, sulfide quinone reductase; TQR, thiosulfate quinone reductase; $\mathrm{TetH}$, tetrathionate reductase; TST, thiosulfate sulfur transferase (rhodanese); HDR, heterodisulfide reductase; APS reductase, adenosine phosphosulfate reductase; SAT, sulfate adenylate transferase (sulfate adenylyltransferase, ATP sulfurylase); SiR, sulfite reductase; Ttr, tetrathionate reductase; SOR, sulfur oxygenase reductase; Psr, polysulfide reductase.

overexpression in S. acidophilus TPY. The SOR expression plasmid pTrc99A_sor_oriT was successfully transferred from heterotrophic E. coli S17-1 to chemoautotrophic S. acidophilus TPY via conjugation of these two strains despite their considerable differences in cultivation conditions. Western blot analysis showed a $35 \mathrm{kDa}$ band in the total protein sample of recombinant $S$. acidophilus TPY-SOR (Figure 2, lane 2), indicating that SOR was successfully overexpressed. It was in accordance with the protein size of SOR from S. acidophilus TPY reported before (Zhang et al., 2013). A 
faint band at the position about $22 \mathrm{kDa}$ was present in the total protein sample of recombinant $S$. acidophilus TPYSOR (Figure 2, lane 2). Searching in the whole 3754 peptide sequences of the $S$. acidophilus TPY (GenBank accession number: CP002901) using BioEdit program with $6 \times$ His tag sequence as the query revealed that the protein SAM-dependent methyltransferase (TPY_0930) with 202 amino acid residues and $22.7 \mathrm{kDa}$ molecule mass possessed a $7 \times$ His sequence.

\section{Effect of SOR Overexpression on S. acidophilus TPY-SOR}

S. acidophilus TPY and S. acidophilus TPY-SOR were cultivated under the same conditions with $S^{0}$ as energy source to investigate changes in $\mathrm{pH}$, oxidation/reduction potentials (ORPs), and amount of $\mathrm{SO}_{4}^{2-}$ released into the medium of the recombinant strain. As shown in Figure 3A, when $\mathrm{S}^{0}$ was used as the substrate, the recombinant had an obvious $\mathrm{SO}_{4}^{2-}$ accumulation increase compared with the wild type in the last 8 days (day 3-11) of cultivation. The maximum $\mathrm{SO}_{4}^{2-}$ concentration in the medium was $13.76 \mathrm{~g} / \mathrm{L}$, which was $30.8 \%$ higher than in the wild-type culture $(10.52 \mathrm{~g} / \mathrm{L})$. However, the $\mathrm{SO}_{4}^{2-}$ concentration in the recombinant culture was slightly less than that in the wildtype in the first 2 days of cultivation. Thus, the two curves cross between day 2 and 3 (Figure 3A). The ORPs curves were similar to the $\mathrm{SO}_{4}^{2-}$ concentration curves, where the recombinant ORP-value was higher than that of the wild-type strain after the time point where the curves crossed (Figure 3B). On day 11 , the maximum ORP-value of the recombinant was 337.5 $\mathrm{mV}$, which was $5.0 \%$ higher than that of the wild-type strain

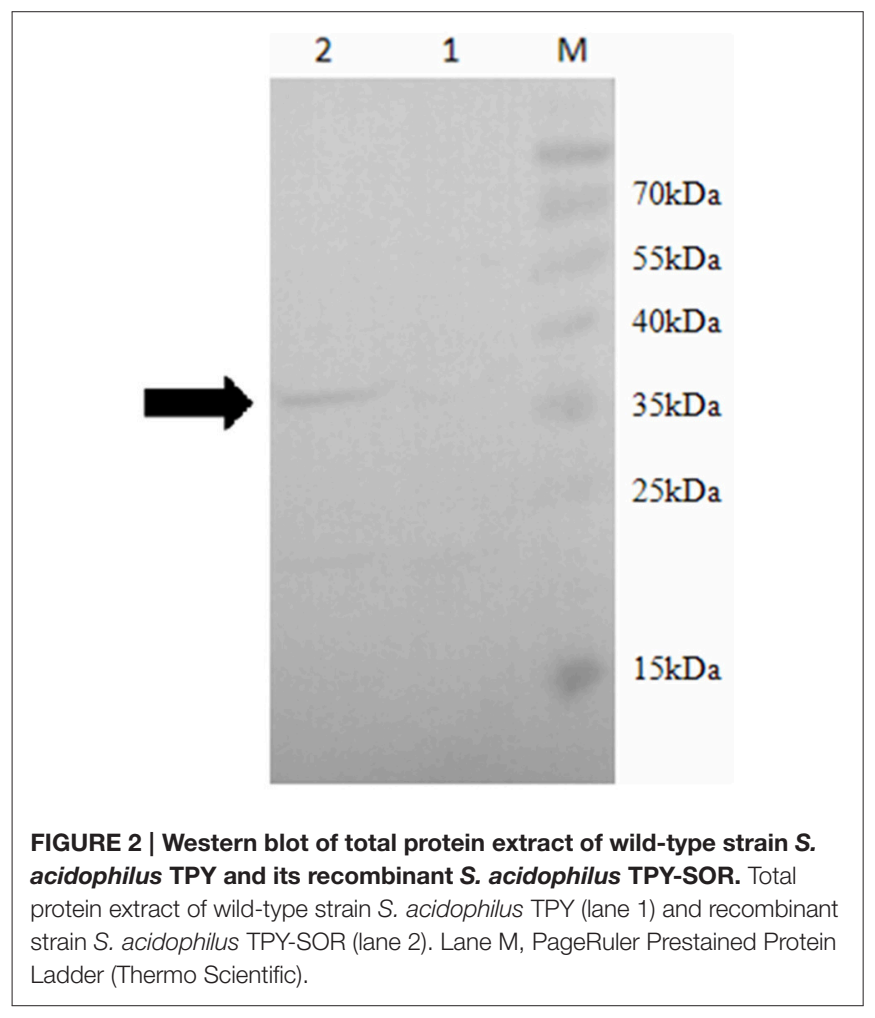

(321.4 mV; Figure 3B). In contrast, the $\mathrm{pH}$ curves showed an opposite trend, with recombinant culture having lower $\mathrm{pH}$ than the wild type after the curves crossed on day 2 (Figure 3C). On day 11 , the minimum $\mathrm{pH}$ of the recombinant was 1.17 , which was $20.4 \%$ lower than the $\mathrm{pH}$ of the wild-type culture (1.47; Figure 3C).
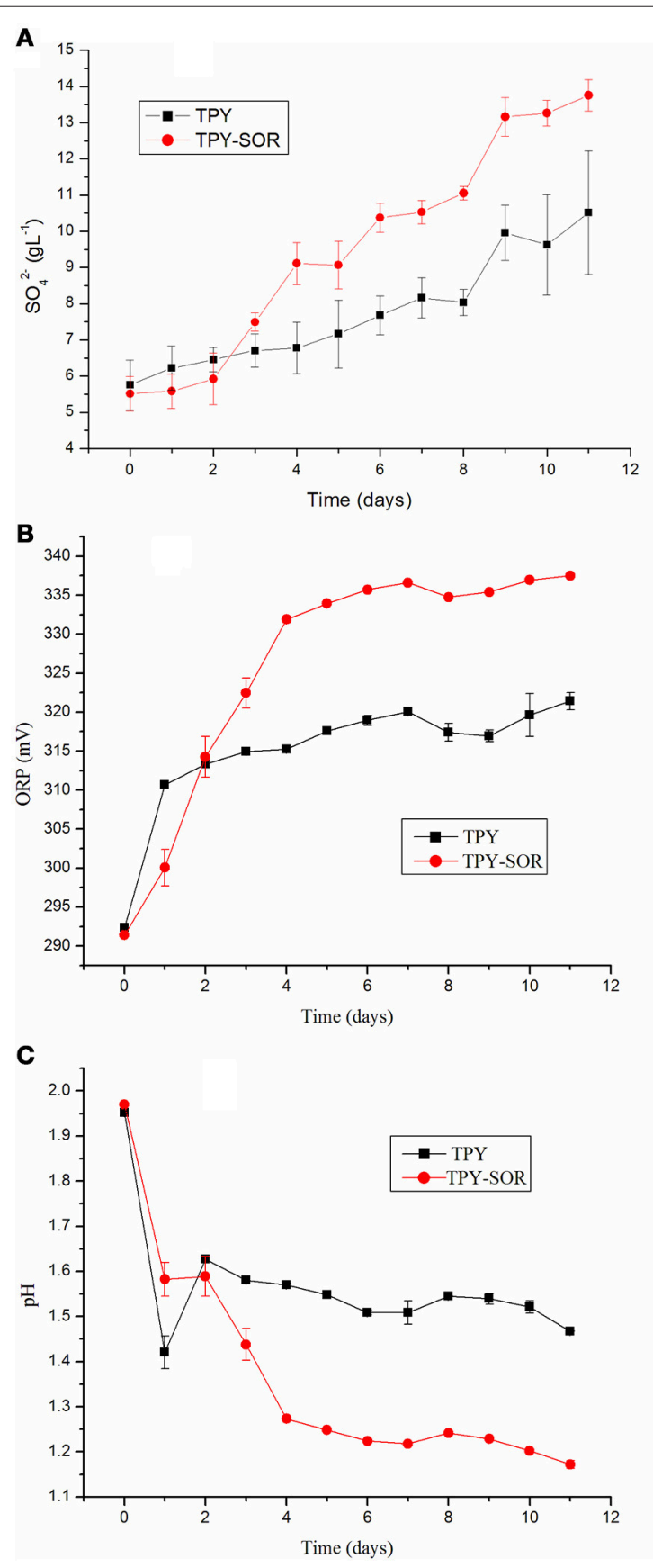

FIGURE 3 | Characterization of wild-type strain S. acidophilus TPY and recombinant $S$. acidophilus TPY-SOR cultured under the same conditions with elemental sulfur $\left(\mathrm{S}^{0}\right)$ as substrate. $\mathrm{SO}_{4}^{2-}(\mathrm{A})$, oxidation/reduction potential (ORP; B), and pH (C) curves for the wild-type (TPY) and recombinant (TPY-SOR) strains. 


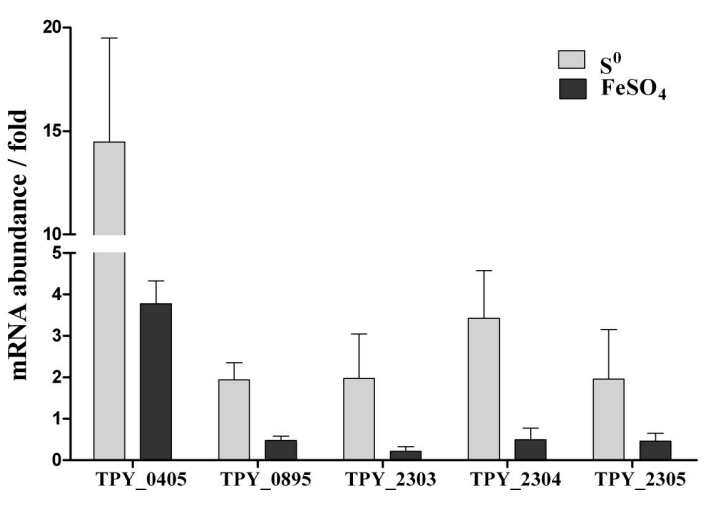

FIGURE 4 | Effect of energy source on relative mRNA abundance of representative genes in the sulfur metabolism pathways in recombinant S. acidophilus TPY-SOR. All values are expressed as $n$-fold relative to the level of transcripts of the same gene in the wild-type $S$. acidophilus TPY. TPY_0405, sor encoding sulfur oxygenase reductase (SOR); TPY_0895, tetH encoding tetrathionate hydrolase (TetH); TPY_2303, sat encoding sulfate adenylyltransferase (SAT); TPY_2304, cysH encoding adenosine phosphosulfate (APS) reductase; TPY_2305, cys/ encoding sulfite reductase $(\mathrm{SiR})$.

\section{Analysis of mRNA Abundance in S. acidophilus TPY-SOR}

Levels of transcripts of representative genes in the sulfur metabolism pathways in the recombinant S. acidophilus TPYSOR cultured in the presence of $\mathrm{S}^{0}$ and $\mathrm{FeSO}_{4}$ were analyzed using rRT-qPCR (Figure 4). All values are expressed as n-fold relative to the level of transcripts of the same gene in the wildtype $S$. acidophilus TPY. In the presence of $S^{0}$, the level of transcripts of the sor gene (TPY_0405) in S. acidophilus TPYSOR increased by 14.46 -fold compared with S. acidophilus TPY (Figure 4). In addition to the sor gene, the transcription levels of other important genes in the sulfur metabolism pathways also increased; these include tetH (TPY_0895), encoding a tetrathionate hydrolase (TetH), with a 1.94-fold increase; sat (TPY_2303), encoding sulfate adenylyltransferase (SAT); cysH (TPY_2304), encoding adenosine phosphosulfate (APS) reductase; and cysI (TPY_2305) encoding sulfite reductase (SiR) in the sulfate reducing operon with increase folds of 1.97, 3.42, and 1.95, respectively (Figure 4). Under conditions of growth in $\mathrm{FeSO}_{4}$, the level of sor gene (TPY_0405) transcripts in $S$. acidophilus TPY-SOR increased by 3.77-fold compared with $S$. acidophilus TPY (Figure 4). However, the transcription level of other representative genes involved in sulfur metabolism pathways generally decreased, including tetH (TPY_0895), sat (TPY_2303), cysH (TPY_2304), and cysI (TPY_2305) with 0.47-, 0.21-, 0.49-, and 0.46-fold decreases, respectively (Figure 4).

\section{DISCUSSION}

\section{The Key Role of Sulfite Reductase (SiR)}

In this study, the sulfur metabolism pathways of S. acidophilus TPY were proposed based on comparative transcriptomic analyses. The mRNA abundance of sulfur metabolism related genes in $\mathrm{S}^{0}$ and $\mathrm{FeSO}_{4}$ culture conditions was quite different with that of the type strain A. ferrooxidans ATCC 23270. In the type strain A. ferrooxidans ATCC 23270, the sulfur metabolismrelated genes were significantly increased under conditions of growth in $\mathrm{S}^{0}$ and decreased in $\mathrm{FeSO}_{4}$ (Quatrini et al., 2009). In addition, in the A. ferrooxidans ATCC 23270 genome (GenBank: $\mathrm{CP} 001219)$, the cysI gene encodes a sulfite reductase (NADPH) hemoprotein beta-component with locus tag of AFE_3122 (Zeng et al., 2008). However, in this study, it is interesting that most genes and operons involved in sulfur and RISCs metabolism in $S$. acidophilus TPY were decreased when grown in the presence of $\mathrm{S}^{0}$ and increased in the presence of $\mathrm{FeSO}_{4}$. In this study, it was speculated that the sulfite reductase ( $\mathrm{SiR}$ ) in S. acidophilus TPY may involve in the dissimilatory sulfate reduction and play an important role when $\mathrm{FeSO}_{4}$ serves as energy resource (Figure 1). It still could not be excluded as a sulfite reductase ( $\mathrm{SiR}$ ) involving in the assimilatory sulfate reduction (Figure 1). In E. coli, the sulfite reductase $(\mathrm{SiR})$ is a $780 \mathrm{kDa}$ soluble complex composed of two proteins, a flavoprotein (SiR-FP) and a metalloprotein (SiR-HP; Zeghouf et al., 2000). In S. acidophilus TPY, only the SiR-HP-encoding gene, cysI (TPY_2305, 9.03-fold increase in $\mathrm{FeSO}_{4}$ ) was found. The amino acid sequence of sulfite reductase (SiR) of S. acidophilus TPY has $34.51 \%$ identity with that of type strain A. ferrooxidans ATCC 23270. The presence of SiR-HP in S. acidophilus TPY would promote the reduction of sulfate to sulfide under conditions of aerobic growth in $\mathrm{FeSO}_{4}$. Subsequently, sulfide would be changed into other RISCs. Otherwise, the genes and operons involved in sulfur and RISCs metabolism in $S$. acidophilus TPY would not be increased in the $\mathrm{FeSO}_{4}$ cultivation condition. Thus, more $\mathrm{SO}_{4}^{2-}$ available in the presence of $\mathrm{FeSO}_{4}$ than in the presence of $\mathrm{S}^{0}$ increased transcription of genes in the sulfate reducing operon (Table 1). SiR mostly exists in sulfate reducing bacteria (SRB) which usually grow in anaerobic conditions (Wang et al., 2008). However, some SRB are reported to be oxygen tolerant (Kjeldsen et al., 2004). Although most of the genes, enzymes and operons involved in the sulfur metabolism have been reported in Sulfobacillus thermosulfidooxidans, the key enzyme SiR which plays an important role in S. acidophilus TPY is missing in S. thermosulfidooxidans (Guo et al., 2014; Justice et al., 2014). Thus, S. acidophilus TPY not only could oxidize RISCs to sulfate ultimately but also reduce sulfate to RISCs, making sulfur redox metabolism a cycle.

\section{mRNA Abundance Analysis of S. acidophilus TPY-SOR Confirmed the Proposed Sulfur Metabolism Pathways}

The transcription level of sor gene in the recombinant S. acidophilus TPY-SOR increased by 14.46 - and 3.77-fold compared with $S$. acidophilus TPY in the $\mathrm{S}^{0}$ and $\mathrm{FeSO}_{4}$ culture conditions, respectively. This finding indicates that introduction of extra copies of the sor gene under the control of the Trc promoter significantly increased the level of sor mRNA in $S$. acidophilus TPY-SOR. The increased $\mathrm{SO}_{4}^{2-}$ accumulation in the SOR-overexpressing recombinant compared with the wild type in the late stage of growth (Figure 3A) indicating the increased transportation of $\mathrm{S}^{0}$ into cell and transformation of $\mathrm{S}^{0}-\mathrm{SO}_{4}^{2-}$. 
Therefore, the higher fold increase of the recombinant in the $S^{0}$ culture condition indicating the higher transcription of the chromosomal copy of sor gene under the native promoter which was induced by higher transported $S^{0}$. Obviously, the extra copies of the sor gene under the control of the Trc promoter in the plasmid could not be induced by $S^{0}$. According to the sulfur metabolism pathways proposed above, TetH, SAT, and APS reductase play important roles in the oxidation of RISCs produced from oxidation of sulfur to sulfate. In this study, it was presumed that the overexpression of SOR in $S$. acidophilus TPY-SOR resulted in increase of thiosulfate and sulfite when it was cultivated in the $S^{0}$ containing medium (Figure 1). SOR is able to catalyze the disproportionation of $S^{0}$, producing sulfite, thiosulfate, and sulfide. Thiosulfate and sulfite could be transferred to tetrathionate and APS by TQR and APS reductase, respectively. Subsequently, more tetrathionate and APS accumulated to serve as the substrates of TetH and SAT, respectively, and both produce sulfate (Figure 1). In the $S^{0}$ cultivation condition, the increased transcript levels of the respective genes (tetH, TPY_0895; cysH, TPY_2304; and cysI, TPY_2305) may be one of the reasons for the increased sulfur-oxidation activity of $S$. acidophilus TPY-SOR (Figure 4). This phenomenon was in accordance with the sulfate accumulation increase in S. acidophilus TPY-SOR under conditions of growth in $S^{0}$ (Figure 3A). The level of transcripts of the cysI gene, encoding SiR, increased by 1.95 -fold maybe due to the accumulation of its substrate, sulfite. Under conditions of growth in $\mathrm{FeSO}_{4}$, according to the proposed sulfur metabolism pathways (Figure 1), it is presumed that the increased sulfite (one of the products of SOR) accumulation in S. acidophilus TPYSOR simultaneously inhibited the transcription of $s a t$ and $c y s H$, which encode SAT and APS reductase, respectively, participating in the conversion of sulfate to sulfite (Figure 4). Similarly, the deduced thiosulfate accumulation increase in S. acidophilus TPY-SOR resulted in decreased transcription of tet $H$, which encodes tetrathionate hydrolase and also produces thiosulfate. The simultaneous accumulation increase of sulfite and sulfide decreased the transcription of cysI, which encodes SiR for converting sulfite to sulfide.

\section{Sulfur Metabolism Changed by the Overexpression of SOR}

Overexpression of SOR in the recombinant accelerated the oxidation of $\mathrm{S}^{0}$ to RISCs, and ultimately $\mathrm{SO}_{4}^{2-}$, after the time point at which the curves crossed. Accumulation increase of RISCs and $\mathrm{SO}_{4}^{2-}$ in the recombinant culture resulted in the higher ORP and lower $\mathrm{pH}$-values compared with the wild type. It is not an efficient way to produce electrons from sulfur atoms oxidized by SOR when sulfur atoms in cytoplasm are insufficient due to delay in sulfur activation and transport at the early stage of growth in $\mathrm{S}^{0}$-containing medium. At the early growth stage (before the time point at which the curves cross) in $\mathrm{S}^{0}$-containing medium, occupation of sulfur atoms induced by overexpression of SOR in the recombinant made shifting of the sulfur oxidation pathways from SOR to other efficient pathways impossible. In contrast, when sulfur atoms are sufficient at the late growth stage in the presence of $S^{0}$, SOR overexpression in the recombinant oxidizes the sulfur atoms to produce other sulfur compounds, which enter other cytoplasmic sulfur oxidation pathways to produce electrons. This might be the reason for the $\mathrm{SO}_{4}^{2--}$ accumulation increase, higher ORP, and lower $\mathrm{pH}$ of the SORoverexpressing recombinant compared with the wild type in the late stage of growth. This hypothesis is also supported by the description of an obvious growth increase in a $\Delta$ sor mutant of A. caldus MH-04 observed in the first 6 (of a total of 12) days of culture in $S^{0}$-containing medium (Quatrini et al., 2009). Sulfate plays an important role in the direct leaching of metals from mineral ores: $\mathrm{MS}+\mathrm{H}_{2} \mathrm{SO}_{4}+1 / 2 \mathrm{O}^{2} \rightarrow \mathrm{MSO}_{4}+\mathrm{S}^{0}$ $+\mathrm{H}_{2} \mathrm{O}$, where $\mathrm{M}$ is a divalent metal (Suzuki, 2001). Leaching microorganisms will backfill the consumption of sulfate: $\mathrm{S}^{0}+$ $1 / 2 \mathrm{O}^{2}+\mathrm{H}_{2} \mathrm{O} \rightarrow \mathrm{H}_{2} \mathrm{SO}_{4}$ (Suzuki, 2001). Generally, lower $\mathrm{pH}$ will facilitate the sphalerite leaching (Mousavi et al., 2008; Vilcáez et al., 2009). The increased sulfate production in the SOR-overexpression strain indicated its potential metals leaching advantage via the direct action.

\section{Identification of Tetrathionate Reductase (Ttr)}

The ability to respire tetrathionate based on $t$ tr operon is characteristic of certain genera of Enterobacteriaceae such as Salmonella typhimurium (Hensel et al., 1999). Compared with TtrC, protein encoded by TPY_3700 showed significant sequence similarity to polysulfide reductase subunit C (PsrC). However, bioinformatics analysis indicated that the protein encoded by TPY_3700 owns typical conserved domain of TtrC. Hensel et al. also indicated that $\operatorname{TtrC}$ exhibits statistically significant sequence similarity to PsrC (Hensel et al., 1999). In addition, $\operatorname{ttr} A, \operatorname{ttr} B$, and TPY_3700 are clustered together and orientate in the same direction. As a result, TPY_3700 was predicted to be $\operatorname{ttrC}$. According to bioinformatics analysis, TPY_3702 was predicted to be $t$ trD. The blast results of TtrD a.a. sequence from NCBI (National Center for Biotechnology Information) showed a conserved domain of TorD. Besides, protein-protein interaction databases of UniProt also showed that TtrD interacts with TtrA. TtrD belongs to the TorD/DmsD family chaperone, and binds specifically to the Tat signal peptide of the TtrA (Coulthurst et al., 2012).

\section{CONCLUSIONS}

Sulfobacillus acidophilus TPY is a moderately thermoacidophilic Gram-positive bacterium with potential advantages in bioleaching. In this study, the sulfur metabolism pathways of S. acidophilus TPY with redox cycles were proposed via comparative transcriptomic analyses and RT-qPCR experiments. In order to confirm the sulfur metabolism pathways, SOR overexpression in S. acidophilus TPY and subsequent mRNA abundance analyses of sulfur metabolism related genes were carried out. The recombinant S. acidophilus TPY-SOR had higher sulfur metabolism activity resulting in $\mathrm{SO}_{4}^{2-}$-accumulation increase, higher oxidation/reduction potentials (ORPs) and lower $\mathrm{pH}$ than the wild type in the late growth stage of $\mathrm{S}^{0}$ 
culture condition. The transcribed profile of sor gene and other sulfur metabolism related genes in both $\mathrm{S}^{0}$ and $\mathrm{FeSO}_{4}$ culture conditions confirmed the proposed sulfur metabolism pathways. This is the first attempt to characterize the sulfur metabolism pathways of Gram-positive S. acidophilus and also the first report of genetic manipulation of this species of Gram-positive moderate thermoacidophile.

\section{AVAILABILITY OF DATA AND MATERIALS}

The genome sequence of $S$. acidophilus TPY was deposited on GenBank with accession number of CP002901. The RNA-Seq reads have been deposited in GenBank with accession number SRP055734.

\section{AUTHOR CONTRIBUTIONS}

All authors have read and approved the manuscript. WG and $\mathrm{XC}$ Design, acquisition of data, analysis and interpretation of data, drafting and revising the manuscript. HJZ, WZ, YW, and

\section{REFERENCES}

Acevedo, F. (2000). The use of reactors in biomining processes. Electron. J. Biotechnol. 3, 184-194. doi: 10.2225/vol3-issue3-fulltext-4

Agterdenbos, J., and Martinius, N. (1964). Theoretical considerations on the indirect determination of anions: determination of sulphate with barium chloranilate. Talanta 11, 875-885. doi: 10.1016/0039-9140(64)80115-6

Amann, E., Ochs, B., and Abel, K. J. (1988). Tightly regulated tac promoter vectors useful for the expression of unfused and fused proteins in Escherichia coli. Gene 69, 301-315. doi: 10.1016/0378-1119(88)90440-4

Audic, S., and Claverie, J. M. (1997). The significance of digital gene expression profiles. Genome Res. 7, 986-995.

Auernik, K. S., Maezato, Y., Blum, P. H., and Kelly, R. M. (2008). The genome sequence of the metal-mobilizing, extremely thermoacidophilic archaeon Metallosphaera sedula provides insights into bioleaching-associated metabolism. Appl. Environ. Microbiol. 74, 682-692. doi: 10.1128/AEM.0201907

Berks, B. C., Sargent, F., and Palmer, T. (2000). The Tat protein export pathway. Mol. Microbiol. 35, 260-274. doi: 10.1046/j.1365-2958.2000.01719.x

Brierley, J. A. (1990). Acdidophilic thermophilic archaebacteria: potential application for metals recovery. FEMS Microbiol. Lett. 75, 287-291. doi: 10.1111/j.1574-6968.1990.tb04102.x

Brierley, J. A., and Brierley, C. L. (2001). Present and future commercial applications of biohydrometallurgy. Hydrometallurgy 59, 233-239. doi: 10.1016/S0304-386X(00)00162-6

Brune, K. D., and Bayer, T. (2012). Engineering microbial consortia to enhance biomining and bioremediation. Front. Microbiol. 3:203. doi: 10.3389/fmicb.2012.00203

Chen, L., Ren, Y., Lin, J., Liu, X., Pang, X., and Lin, J. (2012). Acidithiobacillus caldus sulfur oxidation model based on transcriptome analysis between the wild type and sulfur oxygenase reductase defective mutant. PLOS ONE 7:e39470. doi: 10.1371/journal.pone.0039470

Coulthurst, S. J., Dawson, A., Hunter, W. N., and Sargent, F. (2012). Conserved signal peptide recognition systems across the prokaryotic domains. Biochemistry 51, 1678-1686. doi: 10.1021/bi201852d

Dahl, C., Franz, B., Hensen, D., Kesselheim, A., and Zigann, R. (2013). Sulfite oxidation in the purple sulfur bacterium Allochromatium vinosum: identification of SoeABC as a major player and relevance of SoxYZ in the process. Microbiology 159, 2626-2638. doi: 10.1099/mic.0.071019-0
HBZ Acquisition of data, interpretation of data, revising the manuscript.

\section{ACKNOWLEDGMENTS}

The study was financially supported by grants from the National Key Basic Research Program of China (973 Program) 2015CB755903, the Natural Science Foundation of China (41306166), the Scientific Research Project of the Marine Public Welfare Industry of China (201205020), the Natural Science Foundation of Fujian Province, China (2016J05079), and the Scientific Research Foundation of Third Institute of Oceanography, SOA (NO. 2013022).

\section{SUPPLEMENTARY MATERIAL}

The Supplementary Material for this article can be found online at: http://journal.frontiersin.org/article/10.3389/fmicb. 2016.01861/full\#supplementary-material

De Jong Gah, H. W., Bos, P., and Kuenen, J. G. (1997). Polythionate degradation by tetrathionate hydrolase of Thiobacillus ferrooxidans. Microbiology 143, 499-504. doi: 10.1099/00221287-143-2-499

Dopson, M., and Johnson, D. B. (2012). Biodiversity, metabolism and applications of acidophilic sulfur-metabolizing microorganisms. Environ. Microbiol. 14, 2620-2631. doi: 10.1111/j.1462-2920.2012.02749.x

Ghosh, W., and Dam, B. (2009). Biochemistry and molecular biology of lithotrophic sulfur oxidation by taxonomically and ecologically diverse bacteria and archaea. FEMS Microbiol. Rev. 33, 999-1043. doi: 10.1111/j.15746976.2009.00187.x

Guo, X., Yin, H., Liang, Y., Hu, Q., Zhou, X., Xiao, Y., et al. (2014). Comparative genome analysis reveals metabolic versatility and environmental adaptations of Sulfobacillus thermosulfidooxidans strain ST. PLoS ONE 9:e99417. doi: 10.1371/journal.pone.0099417

Hensel, M., Hinsley, A. P., Nikolaus, T., Sawers, G., and Berks, B. C. (1999). The genetic basis of tetrathionate respiration in Salmonella typhimurium. Mol. Microbiol. 32, 275-287. doi: 10.1046/j.1365-2958.1999. 01345.x

Hoang, T. T., Karkhoff-Schweizer, R. R., Kutchma, A. J., and Schweizer, H. P. (1998). A broad-host-range Flp-FRT recombination system for sitespecific excision of chromosomally-located DNA sequences: application for isolation of unmarked Pseudomonas aeruginosa mutants. Gene 212, 77-86. doi: 10.1016/S0378-1119(98)00130-9

Johnson, D. B., Kanao, T., and Hedrich, S. (2012). Redox transformations of iron at extremely low pH: fundamental and applied aspects. Front. Microbiol. 3:96. doi: $10.3389 /$ fmicb. 2012.00096

Joubert, T. M. (2008). Towards a Genetic System for the Genus Sulfobacillus. Master's Thesis, University of Stellenbosch.

Justice, N. B., Norman, A., Brown, C. T., Singh, A., Thomas, B. C., and Banfield, J. F. (2014). Comparison of environmental and isolate Sulfobacillus genomes reveals diverse carbon, sulfur, nitrogen, and hydrogen metabolisms. BMC Genomics 15:1107. doi: 10.1186/1471-2164-15-1107

Kjeldsen, K. U., Joulian, C., and Ingvorsen, K. (2004). Oxygen tolerance of sulfatereducing bacteria in activated sludge. Environ. Sci. Technol. 38, 2038-2043. doi: 10.1021/es034777e

Kletzin, A., Urich, T., Müller, F., Bandeiras, T. M., and Gomes, C. M. (2004). Dissimilatory oxidation and reduction of elemental sulfur in thermophilic archaea. J. Bioenerg. Biomembr. 36, 77-91. doi: 10.1023/B:JOBB.0000019600. $36757.8 \mathrm{c}$ 
Li, B., Chen, Y., Liu, Q., Hu, S., and Chen, X. (2011). Complete genome analysis of Sulfobacillus acidophilus strain TPY, isolated from a hydrothermal vent in the Pacific Ocean. J. Bacteriol. 193, 5555-5556. doi: 10.1128/JB.05684-11

Li, R., Li, Y., Fang, X., Yang, H., Wang, J., Kristiansen, K., et al. (2009). SNP detection for massively parallel whole-genome resequencing. Genome Res. 19, 1124-1132. doi: 10.1101/gr.088013.108

Liu, Y., Lin-Wang, K., Deng, C., Warran, B., Wang, L., Yu, B., et al. (2015). Comparative transcriptome analysis of white and purple potato to identify genes involved in anthocyanin biosynthesis. PLoS ONE 10:e0129148. doi: $10.1145 / 2818302$

Livak, K. J., and Schmittgen, T. D. (2001). Analysis of relative gene expression data using real-time quantitative PCR and the 2(-Delta Delta C(T)) Method. Methods 25, 402-408. doi: 10.1006/meth.2001.1262

Mangold, S., Valdés, J., Holmes, D., and Dopson, M. (2011). Sulfur metabolism in the extreme acidophile Acidithiobacillus caldus. Front. Microbiol. 2:17. doi: 10.3389/fmicb.2011.00017

Merroun, M. L., Geipel, G., Nicolai, R., Heise, K. H., and SelenskaPobell, S. (2003). Complexation of uranium (VI) by three eco-types of Acidithiobacillus ferrooxidans studied using time-resolved laser-induced fluorescence spectroscopy and infrared spectroscopy. Biometals 16, 331-339. doi: 10.1023/A:1020612600726

Mihara, H., and Esaki, N. (2002). Bacterial cysteine desulfurases: their function and mechanisms. Appl. Microbiol. Biotechnol. 60, 12-23. doi: 10.1007/s00253-0021107-4

Mortazavi, A., Williams, B. A., Mccue, K., Schaeffer, L., and Wold, B. (2008). Mapping and quantifying mammalian transcriptomes by RNA-Seq. Nat. Methods 5, 621-628. doi: 10.1038/nmeth.1226

Mousavi, S. M., Yaghmaei, S., Vossoughi, M., Roostaazad, R., Jafari, A., Ebrahimi, M., et al. (2008). The effects of $\mathrm{Fe}$ (II) and $\mathrm{Fe}$ (III) concentration and initial pH on microbial leaching of low-grade sphalerite ore in a column reactor. Bioresour. Technol. 99, 2840-2845. doi: 10.1016/j.biortech.2007.06.009

Murphy, M. J., Siegel, L. M., Tove, S. R., and Kamin, H. (1974). Siroheme: a new prosthetic group participating in six-electron reduction reactions catalyzed by both sulfite and nitrite reductases. Proc. Natl. Acad. Sci. U.S.A. 71, 612-616. doi: 10.1073/pnas.71.3.612

Norris, P. R., Clark, D. A., Owen, J. P., and Waterhouse, S. (1996). Characteristics of Sulfobacillus acidophilus sp. nov. and other moderately thermophilic mineral-sulphide-oxidizing bacteria. Microbiology 142(Pt 4), 775-783. doi: 10.1099/00221287-142-4-775

Olson, G. J., Brierley, J. A., and Brierley, C. L. (2003). Bioleaching review part B: progress in bioleaching: applications of microbial processes by the minerals industries. Appl. Microbiol. Biotechnol. 63, 249-257. doi: 10.1007/s00253-0031404-6

Peng, J. B., Yan, W. M., and Bao, X. Z. (1994). Plasmid and transposon transfer to Thiobacillus ferrooxidans. J. Bacteriol. 176, 2892-2897.

Qin, N., Tan, X., Jiao, Y., Liu, L., Zhao, W., Yang, S., et al. (2014). RNA-Seqbased transcriptome analysis of methicillin-resistant Staphylococcus aureus biofilm inhibition by ursolic acid and resveratrol. Sci. Rep. 4:5467. doi: 10.1038/srep05467

Quatrini, R., Appia-Ayme, C., Denis, Y., Jedlicki, E., Holmes, D. S., and Bonnefoy, V. (2009). Extending the models for iron and sulfur oxidation in the extreme acidophile Acidithiobacillus ferrooxidans. BMC Genomics 10:394. doi: 10.1186/1471-2164-10-394
Rawlings, D. E. (2002). Heavy metal mining using microbes. Annu. Rev. Microbiol. 56, 65-91. doi: 10.1146/annurev.micro.56.012302.161052

Rawlings, D. E., Dew, D., and Du Plessis, C. (2003). Biomineralization of metal-containing ores and concentrates. Trends Biotechnol. 21, 38-44. doi: 10.1016/S0167-7799(02)00004-5

Robertson, W. J., Kinnunen, P. H. M., Plumb, J. J., Franzmann, P. D., Puhakka, J. A., Gibson, J., et al. (2002). Moderately thermophilic iron oxidising bacteria isolated from a pyritic coal deposit showing spontaneous combustion. Miner. Eng. 15, 815-822. doi: 10.1016/S0892-6875(02)00130-9

Simon, R., Priefer, U., and Puhler, A. (1983). A broad host range mobilization system for in vivo genetic engineering: transposon mutagenesis in gram negative bacteria. Nat. Biotech. 1, 784-791. doi: 10.1038/nbt1183-784

Suzuki, I. (2001). Microbial leaching of metals from sulfide minerals. Biotechnol. Adv. 19, 119-132. doi: 10.1016/S0734-9750(01)00053-2

Thomas, D., and Surdin-Kerjan, Y. (1997). Metabolism of sulfur amino acids in Saccharomyces cerevisiae. Microbiol. Mol. Biol. Rev. 61, 503-532.

Torma, A. E. (1983). Biotechnology applied to mining of metals. Biotechnol. Adv. 1, 73-80. doi: 10.1016/0734-9750(83)90302-6

Valdes, J., Pedroso, I., Quatrini, R., Dodson, R. J., Tettelin, H., Blake, R. II., et al. (2008). Acidithiobacillus ferrooxidans metabolism: from genome sequence to industrial applications. BMC Genomics 9:597. doi: 10.1186/1471-2164-9-597

Vilcáez, J., Yamada, R., and Inoue, C. (2009). Effect of pH reduction and ferric ion addition on the leaching of chalcopyrite at thermophilic temperatures. Hydrometallurgy 96, 62-71. doi: 10.1016/j.hydromet.2008.08.003

Wang, A., Ren, N., Wang, X., and Lee, D. (2008). Enhanced sulfate reduction with acidogenic sulfate-reducing bacteria. J. Hazard. Mater. 154, 1060-1065. doi: 10.1016/j.jhazmat.2007.11.022

Zeghouf, M., Fontecave, M., and Coves, J. (2000). A simplifed functional version of the Escherichia coli sulfite reductase. J. Biol. Chem. 275, 37651-37656. doi: 10.1074/jbc.M005619200

Zeng, J., Wang, M., Zhang, X., Wang, Y., Ai, C., Liu, J., et al. (2008). Expression, purification and characterization of the sulfite reductase hemo-subunit, SiRHP, from Acidithiobacillus ferrooxidans. Biotechnol. Lett. 30, 1239-1244. doi: 10.1007/s10529-008-9679-4

Zhang, H., Guo, W., Xu, C., Zhou, H., and Chen, X. (2013). Site-specific mutagenesis and functional analysis of active sites of sulfur oxygenase reductase from Gram-positive moderate thermophile Sulfobacillus acidophilus TPY. Microbiol. Res. 168, 654-660. doi: 10.1016/j.micres.2013.04.008

Zhou, H.-B., Zeng, W.-M., Yang, Z.-F., Xie, Y.-J., and Qiu, G.-Z. (2009). Bioleaching of chalcopyrite concentrate by a moderately thermophilic culture in a stirred tank reactor. Bioresour. Technol. 100, 515-520. doi: 10.1016/j.biortech.2008.06.033

Conflict of Interest Statement: The authors declare that the research was conducted in the absence of any commercial or financial relationships that could be construed as a potential conflict of interest.

Copyright (C) 2016 Guo, Zhang, Zhou, Wang, Zhou and Chen. This is an open-access article distributed under the terms of the Creative Commons Attribution License (CC $B Y)$. The use, distribution or reproduction in other forums is permitted, provided the original author(s) or licensor are credited and that the original publication in this journal is cited, in accordance with accepted academic practice. No use, distribution or reproduction is permitted which does not comply with these terms. 